\title{
Growth of Microalgae Scenedesmus sp in Ethanol Vinasse
}

\author{
Nelzy Neyza Vargas Ramirez*, Marcelo Farenzena and Jorge Otávio Trierweiler \\ Departamento de Engenharia Química; Universidade Federal do Rio Grande do Sul; Porto Alegre - RS - \\ Brasil
}

\begin{abstract}
This study evaluated the feasibility of using vinasse as a nutrient source for microalgae cultivation. The Scenedesmus sp was grown in a medium supplemented with vinasse and process variables were optimized using a factorial design and a Central Composite Design (CCD). The factorial design results showed that it was possible to cultivate microalgae at concentrations of up to $40 \%$ of vinasse in the culture medium. The CCD results showed that the light intensity and vinasse concentration influenced the amount of biomass produced.
\end{abstract}

Key words: vinasse, microalgae, Scenedesmus sp, photobioreactor air-lift

\section{INTRODUCTION}

Brazil has been producing ethanol in a large scale for automotive fuel for more than 30 years. The country is the second largest world producer of ethanol and is the only country where the biofuels compete with gasoline (Walter 2009). However, this high production provides a huge amount of waste throughout the years. One inherent byproduct of the process is vinasse. For each liter of ethanol produced, 10 to $18 \mathrm{~L}$ of vinasse are generated (Christofoletti et al. 2013). The 2011/2012 harvest yielded approximately 23 million cubic meters of ethanol (Unica 2012), which corresponded to at least 230 million cubic meters of vinasse.

Vinasse is usually used as a fertilizer for agricultural soils due to the presence of nutrients such as nitrogen, phosphorus and potassium. Nevertheless, vinasse presents undesirable characteristics such as an acidic $\mathrm{pH}$, high BOD and unpleasant odors when dumped in open areas. Studies have shown that irrigating crops with vinasse could lead to the contamination of underground water through infiltration, limiting its use (Buchler 1987). Another option is to capture it in a deep well, but underground storage is limited. Brazilian local environmental agencies such as CETESB have established norms for the appropriate discharge of vinasse (CETESB 2006). There are other method such as evaporation to produce animal food and incineration for potassium recovery, but these treatments require high costs (Navarro et al. 2000; Dos Santos et al. 2013). Given the importance of ethanol for the national economy and new restrictions on the use of vinasse, new alternatives should be evaluated. In this context, bioremediation using microalgae could be a promising alternative.

Microalgae have been used at a global scale for different purposes. Aside from their high content of lipid and carbohydrate, microalgae are considered excellent raw material for biofuel production. Microalgae have other advantages as well, such as their fast growth, non-competition with food cultivations and high efficiency in fixing $\mathrm{CO}_{2}$ (Zhao et al. 2013). Due to their composition, microalgae can be used to obtain pigments and

*Author for correspondence: nelzyv@yahoo.es 
also as a nutritional supplement (Brennan and Owende 2010). They can also be used to treat the industrial effluents and sewage. Doria et al. (2012) used Scenedesmus acutus inoculated in wastewater from anaerobic digestion process that resulted in a production of $0.74 \mathrm{~g} / \mathrm{L}$ of biomass in eight days. Oliveira (2013) observed that Scenedesmus sp could be used to treat up to $30 \%$ of domestic effluents (vinasse has similar characteristics) and obtained a biomass production of $0.48 \mathrm{~g} / \mathrm{L}$ in ten days.

Many products derived from these microorganisms, such as biofuels, are still expensive due to several reasons, including the nutrients required for the biomass growth. Thus, the aim of this study was to use vinasse as a source of nutrients in order to provide a promising alternative for cultivating microalgae.

Using vinasse pre-treated by an anaerobic process, España-Gamboa et al. (2011) were able to determine the presence of favorable conditions for microalgae growth. Treatment of beet vinasse using a vinasse concentration of $5 \mathrm{~g} / \mathrm{L}$ (supplemented with Schlösser medium) pre-treated anaerobically using the microalgae Spirulina maxima resulted in a production of $4.8 \mathrm{~g} / \mathrm{L}$ of biomass in eleven days (Barrocal et al. 2010). Marques (2013) worked on diluted vinasse treatment $(2 \mathrm{gCOD} / \mathrm{L})$ using $C$. vulgaris and obtained $0.49 \mathrm{~g} / \mathrm{L}$ in seven days. There is currently no information on specific studies related to the use of Scenedesmus sp to treat this effluent.

The aim of this study was to evaluate the viability of producing microalgae Scenedesmus sp using vinasse as an alternative culture medium that could replace the Guillard Modified Medium.

\section{MATERIALS AND METHODS}

\section{Microorganism}

Microalgae cultures were maintained in $1000 \mathrm{~mL}$ Erlenmeyer flasks with the Guillard Modified culture medium and adapted at different percentages of vinasse at $25^{\circ} \mathrm{C}$ and 3910 lux. When the growth reached the exponential phase, medium volume was increased by a factor of two.

\section{Culture medium}

Although the Guillard Medium's original composition contained vitamins (Stein 1979), they were not added here. The modified medium contained two different solutions which contained $(\mathrm{g} / \mathrm{L})$ macronutrient solution comprising 36.76 $\mathrm{CaCl}_{2} 2 \mathrm{H}_{2} \mathrm{O}, 36.97 \mathrm{MgSO}_{4} \cdot 7 \mathrm{H}_{2} \mathrm{O}, 12.6 \mathrm{NaHCO}_{3}$, $8.71 \mathrm{~K}_{2} \mathrm{HPO}_{4}, 85.01 \quad \mathrm{NaNO}_{3}, 28.42 \quad \mathrm{Na}_{2} \mathrm{SiO}_{3} 9$ $\mathrm{H}_{2} \mathrm{O}$, and micronutrient solution: 4.36 $\mathrm{Na}_{2}$ EDTA, $3.15 \mathrm{FeCl}_{3} 6 \mathrm{H}_{2} \mathrm{O}, 0.01 \mathrm{CuSO}_{4} \cdot 5 \mathrm{H}_{2} \mathrm{O}$, $0.022 \quad \mathrm{ZnSO}_{4} \cdot 7 \mathrm{H}_{2} \mathrm{O}, \quad 0.01 \quad \mathrm{CoCl}_{2} \cdot 6 \mathrm{H}_{2} \mathrm{O}, \quad 0.18$ $\mathrm{MnCl}_{2} 4 \mathrm{H}_{2} \mathrm{O}, 0.006 \quad \mathrm{Na}_{2} \mathrm{MoO}_{4} 2 \mathrm{H}_{2} \mathrm{O}$. Different quantities of these solutions were used in the photobioreactors. The vinasse was supplied by COOPERCANA Ltda. (Porto Xavier, Rio Grande do Sul, Brazil), which contained (mg/L) 7410 BOD, $245.51 \mathrm{~N}, 24.5 \mathrm{P}, 89.18 \mathrm{Ca}, 557.57 \mathrm{~K}$ and $2.30 \mathrm{Na}(\mathrm{pH} 4.0)$.

\section{Operation of photobioreactor}

Air-lift photobioreactors were used to cultivate microalgae. They were made of acrylic with dimensions of $35 \times 17 \times 6 \mathrm{~cm}$ (Fig. 1), with a central plate of $27 \times 17 \mathrm{~cm}$. The culture volume was approximately $3 \mathrm{~L}$. Two porous stones placed in the lower riser provided aeration. Heat exchange in the reactor was attained through a stream of water flowing through 316 stainless steel $1 / 4 "$ tubes.

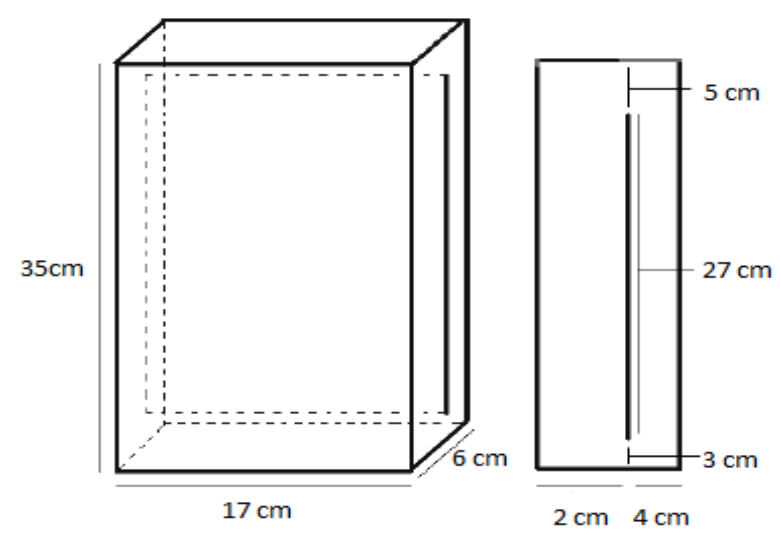

Figure 1 - Air-lift photobioreactor.

The air supply was controlled in the photobioreactors by flow meters. Light intensity was measured on the surface of each photobioreactor. The temperature of the fluid in the refrigeration system was controlled with a digital temperature controller (TIC-Fullgauge 17RGTi). To avoid the loss of culture medium by evaporation, a flask on the photobioreactor lid was added, which allowed the evaporated liquid to condense. A silicone lid covered the orifice sampling to prevent the evaporation (a detailed description of the laboratory apparatus can be obtained in the work of Gris et al. (2013)). 


\section{Biomass measurement}

Dry weight and optical density (OD) were measured daily to determine the microalgae growth and relationship between the dry weight and optical density. OD was measured at $570 \mathrm{~nm}$ wavelength (UV-visible spectrophotometer UV1600 Pró-Análise) and the dry matter was measured by filtering the samples through $0.7 \mu \mathrm{m}$ pre-weighed membranes, which were dried at $100^{\circ} \mathrm{C}$ for $24 \mathrm{~h}$.

\section{Preliminary evaluation of microalgae growth in vinasse}

Erlenmeyer flasks $(250 \mathrm{~mL})$, in triplicate, containing (\%) $0,12.5,25,37.5$ and 50 vinasse in modified Guillard medium were incubated on an orbital shaker (model CT-712RN Cientec) at 125 rpm, $27.5^{\circ} \mathrm{C}$ and light intensity of 6200 lux.

\section{Experimental design}

Two experimental designs were developed after the above study. The first was a factorial design involving temperature, light intensity and percentage of vinasse as variables and the second was the Central Composite Design (CCD) with a photoperiod of $12 \mathrm{~h} / 12 \mathrm{~h}$. Table 1 shows the variables assessed and their levels.

A total of 19 runs were made in CCD (Table 2). The vinasse percentages were altered in this design, with values between 0 and $40 \%$.

Table 1 - Values used in Factorial Design with Vinasse.

\begin{tabular}{lcccc}
\hline Variable & Code & $\mathbf{- 1}$ & $\mathbf{0}$ & $\mathbf{1}$ \\
\hline Temperature $\left[{ }^{\circ} \mathrm{C}\right]$ & $\mathrm{x}_{1}$ & 20 & 27.5 & 35 \\
Vinasse [\%] & $\mathrm{x}_{2}$ & 0 & 25 & 50 \\
Light Intensity [Lux] & $\mathrm{x}_{3}$ & 2400 & 6200 & 10000 \\
\hline
\end{tabular}

Table 2 - Values used in CCD with Vinasse.

\begin{tabular}{|c|c|c|c|c|c|c|}
\hline Variable & Code & -1.68 & -1 & $\mathbf{0}$ & 1 & 1.68 \\
\hline $\begin{array}{l}\text { Temperature } \\
{\left[{ }^{\circ} \mathrm{C}\right]}\end{array}$ & $\mathrm{x}_{1}$ & 20 & 23 & 27.5 & 32 & 35 \\
\hline Vinasse [\%] & $\mathrm{x}_{2}$ & 0 & 8.1 & 20 & 31.9 & 40 \\
\hline $\begin{array}{l}\text { Light Intensity } \\
\text { [Lux] }\end{array}$ & $\mathrm{x}_{3}$ & 2400 & 3940.5 & 6200 & 8459.5 & 10000 \\
\hline
\end{tabular}

\section{RESULTS AND DISCUSSION}

\section{Growth curve determination}

The relationship between the biomass and $\mathrm{OD}_{570}$ is given by:

Biomass $\left[\mathrm{g} . \mathrm{L}^{-1}\right]=0.4669 \cdot \mathrm{OD}_{570 \mathrm{~nm}}-0.0243$

$\mathrm{R}^{2}=0.9889$

This relationship was used as an approximation to dilute the stock culture and reach the desired concentration. The end of the exponential phase was reached after 6 to 10 days of cultivation. Thus, the experiments were maintained for 10 days.

\section{Microalgae growth at different percentages of vinasse}

Figure 2 shows the concentration of biomass produced as a function of percentage of vinasse added to Guillard Modified Medium (blended with up to $50 \%$ vinasse); when vinasse content increased, the biomass production decreased.

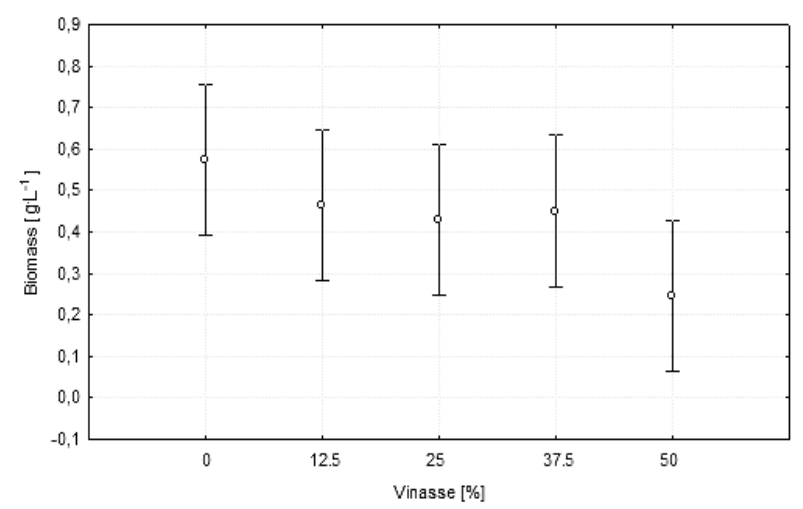

Figure 2 - Growth of Scenedesmus sp at different percentages of vinasse in shaker.

\section{Experimental Design \\ Factorial Design}

Table 3 shows the results of the analysis of variance (ANOVA) at a confidence level of $95 \%$. The bold fonts denoted significant results.

Table 3 - Analysis of variance - factorial design considering temperature, percentage of vinasse and light intensity.

\begin{tabular}{lccccc}
\hline Factor & SS & df & MS & F & p \\
\hline (1)Temperature $\left[{ }^{\circ} \mathbf{C}\right]$ & $\mathbf{0 . 1 5 6 1 5 7}$ & $\mathbf{1}$ & $\mathbf{0 . 1 5 6 1 5 7}$ & $\mathbf{7 6 . 7 6 2 6}$ & $\mathbf{0 . 0 1 2 7 7 8}$ \\
(2)Vinasse $[\%]$ & $\mathbf{0 . 2 0 3 4 4 8}$ & $\mathbf{1}$ & $\mathbf{0 . 2 0 3 4 4 8}$ & $\mathbf{1 0 0 . 0 0 9 6}$ & $\mathbf{0 . 0 0 9 8 5 2}$ \\
(3)Light Intensity [Lux] & $\mathbf{0 . 1 9 6 2 6 2}$ & $\mathbf{1}$ & $\mathbf{0 . 1 9 6 2 6 2}$ & $\mathbf{9 6 . 4 7 7 2}$ & $\mathbf{0 . 0 1 0 2 0 7}$ \\
$\mathbf{1}$ by 2 & $\mathbf{0 . 0 4 5 3 4 6}$ & $\mathbf{1}$ & $\mathbf{0 . 0 4 5 3 4 6}$ & $\mathbf{2 2 . 2 9 0 8}$ & $\mathbf{0 . 0 4 2 0 5 2}$ \\
1 by 3 & 0.018193 & 1 & 0.018193 & 8.9431 & 0.095989 \\
$\mathbf{2}$ by 3 & $\mathbf{0 . 0 9 4 6 9 2}$ & $\mathbf{1}$ & $\mathbf{0 . 0 9 4 6 9 2}$ & $\mathbf{4 6 . 5 4 8 3}$ & $\mathbf{0 . 0 2 0 8 1 5}$ \\
Lack of Fit & 0.004965 & 2 & 0.002482 & 1.2202 & 0.450401 \\
Pure Error & 0.004069 & 2 & 0.002034 & & $\mathrm{R}^{2}=98.8 \%$ \\
Total SS & 0.723130 & 10 & & & \\
\hline
\end{tabular}


Results showed that the percentage of vinasse was the most significant factor, followed by light intensity and then temperature. Evidently not only the linear factors were significant, the interactions between the light intensity-vinasse concentration ( 2 by 3 ) and temperature-vinasse concentration (1 by 2) were significant as well. The variance associated with the lack of fit did not show significance for a confidence level of $95 \%$. The interaction between the light intensity-vinasse concentration could be explained by the fact that the concentration of vinasse affected the penetration of light in the culture. The full model, which was adjusted by using all the parameters, presented $\mathrm{R}^{2}$ equal to $98.8 \%$. The reduced model, adjusted with only significant parameters presented an $\mathrm{R}^{2}$ equal to $96.2 \%$.

The reduced model for biomass in $\mathrm{gL}^{-1}$ as a function of temperature $\left(\mathrm{x}_{1}\right)$, vinasse $\left(\mathrm{x}_{2}\right)$ and light intensity $\left(\mathrm{x}_{3}\right)$ within the range provided in the Table 1, could be given by:

Biomass $=0.488+0.1397 \mathrm{x}_{1}-0.159 \mathrm{x}_{2}+0.157 \mathrm{x}_{3}$ $+0.075 \mathrm{x}_{1} \mathrm{x}_{2}+0.156 \mathrm{x}_{1} \mathrm{x}_{3}$

Figure 3 shows the response surface model based on the Equation (2). It showed that light intensity and temperature contributed positively to biomass production. However, when the percent of vinasse was increased in the medium, biomass production decreased. Figure 3A showed that higher values of light intensity produced more biomass when compared to a biomass production at low light intensity without vinasse. At 10000 lux (maximum point of the interval), good biomass production was achieved with up to $40 \%$ vinasse. Based on these results, the concentration of vinasse was set between $0-40 \%$ in CCD studies.

\section{CCD Studies}

The inoculums were adapted to different vinasse percentages before using them in the CCD experiments in the air-lift photobioreactors. Cultivation lasted 10 days. The analysis of variance (Table 4) showed that the light intensity and vinasse percentage were the most statistically significant parameters, whereas the temperature had no significant effect within the studied range. The linear terms were associated with the letter $\mathrm{L}$ and the quadratic terms with the letter Q.

The full model, which was adjusted by using all the parameters, presented $\mathrm{R}^{2}$ equal to $90.9 \%$. The following equation gave the reduced model encoded for the determination of biomass in $\mathrm{gL}^{-1}$ as a function of vinasse $\left(\mathrm{x}_{1}\right)$ and light intensity $\left(\mathrm{x}_{3}\right)$ within the range provided in the Table 2:

Biomass $=0.3912-0.0953 \mathrm{x}_{1}+0.0915 \mathrm{x}_{3}$

Figure 4 presents the response surface for the reduced model based in the Equation (3). It showed that with increasing light intensity, biomass production also increased but increase in the concentration of vinasse exerted a negative effect on growth.

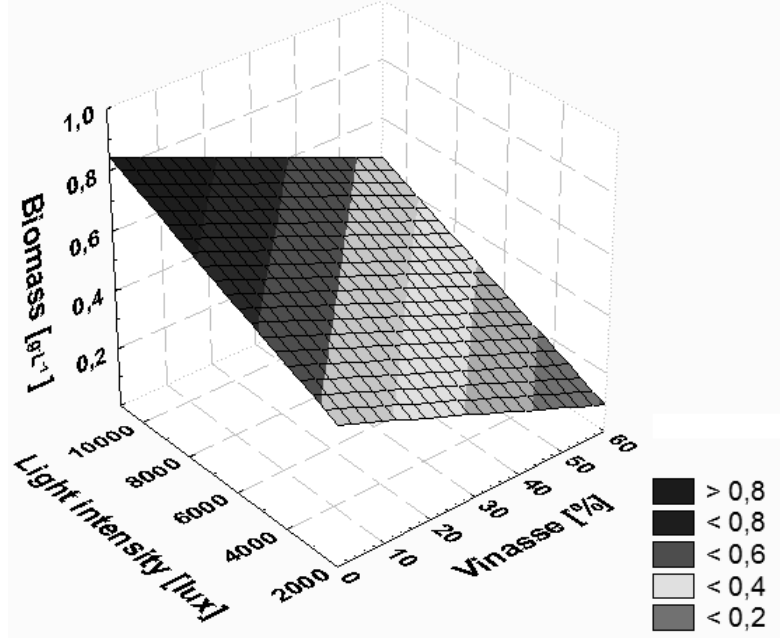

A

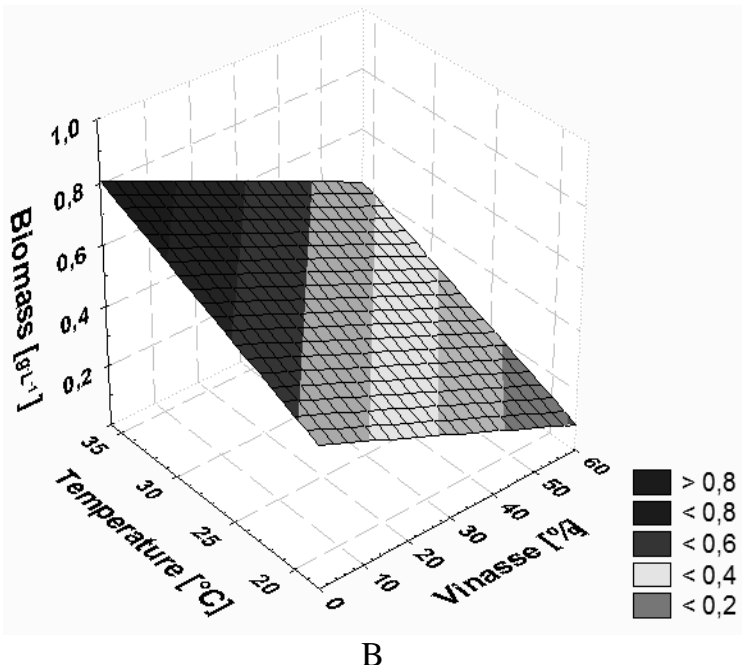

B

Figure 3 - Response surface of the reduced model for production of the Scenedesmus sp using vinasse Factorial Design (A) vinasse - light intensity - biomass (B) vinasse - temperature - biomass. 
Table 4 - Analysis of variance - Central Composite Design considering temperature, percentage of vinasse and light intensity.

\begin{tabular}{lccccc}
\hline Factor & SS & df & MS & F & p \\
\hline Blocks & 0.013122 & 1 & 0.013122 & 9.06401 & 0.057182 \\
$(\mathbf{1})$ Vinasse [\%](L) & $\mathbf{0 . 1 2 4 1 2 8}$ & $\mathbf{1}$ & $\mathbf{0 . 1 2 4 1 2 8}$ & $\mathbf{8 5 . 7 4 3 4 8}$ & $\mathbf{0 . 0 0 2 6 6 5}$ \\
Vinasse [\%](Q) & 0.000595 & 1 & 0.000595 & 0.41095 & 0.567097 \\
$(2)$ Temperature [ $\left.{ }^{\circ} \mathrm{C}\right](\mathrm{L})$ & 0.000071 & 1 & 0.000071 & 0.04935 & 0.838468 \\
Temperature $\left[{ }^{\circ} \mathrm{C}\right](\mathrm{Q})$ & 0.000720 & 1 & 0.000720 & 0.49741 & 0.531470 \\
$(\mathbf{3})$ Light Intensity [Lux](L) & $\mathbf{0 . 1 1 4 4 4 7}$ & $\mathbf{1}$ & $\mathbf{0 . 1 1 4 4 4 7}$ & $\mathbf{7 9 . 0 5 6 7 4}$ & $\mathbf{0 . 0 0 3 0 0 0}$ \\
Light Intensity [Lux](Q) & 0.000642 & 1 & 0.000642 & 0.44328 & 0.553161 \\
1L by 2L & 0.006882 & 1 & 0.006882 & 4.75354 & 0.117320 \\
1L by 3L & 0.002790 & 1 & 0.002790 & 1.92721 & 0.259191 \\
2L by 3L & 0.000652 & 1 & 0.000652 & 0.45051 & 0.550152 \\
Lack of Fit & 0.022189 & 5 & 0.004438 & 3.06548 & 0.192722 \\
Pure Error & 0.004343 & 3 & 0.001448 & & $\mathrm{R}^{2}=90.9 \%$ \\
Total SS & 0.290351 & 18 & & &
\end{tabular}

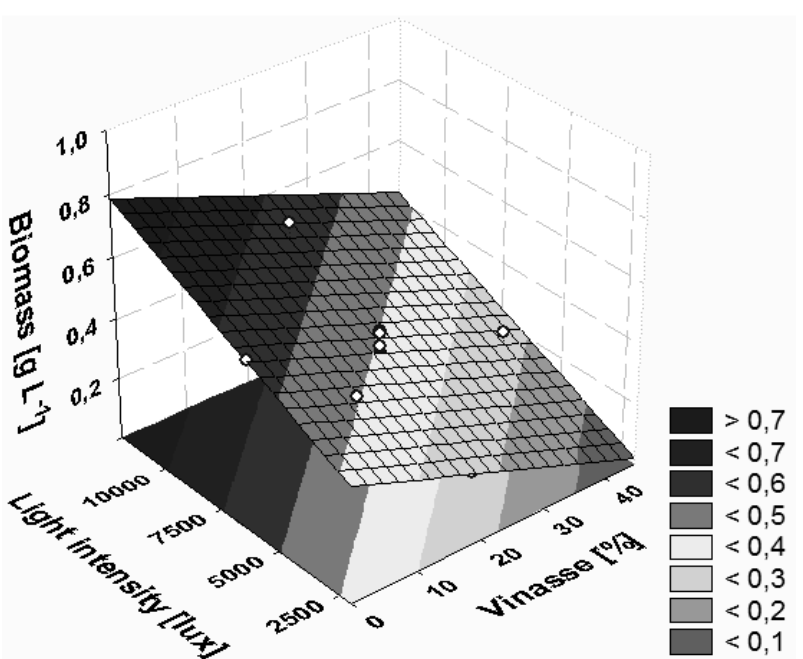

A

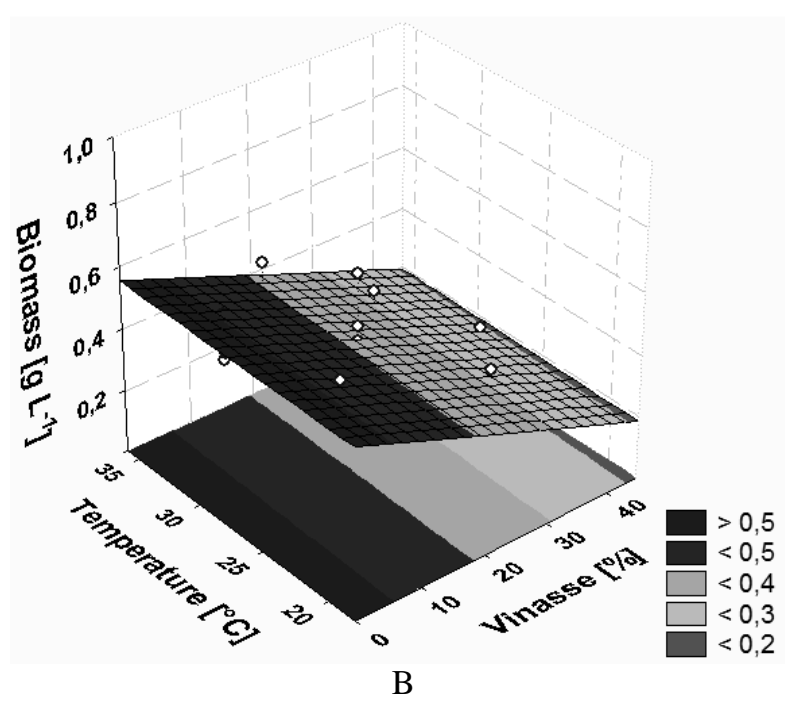

Figure 4 - Response surface of the reduced model for production of the Scenedesmus sp using vinasse - CCD (A) vinasse - light intensity - biomass (B) vinasse - temperature biomass.

The design was used to evaluate and statistically select significant factors as well as identify the effects that influenced the biomass production. From these observations, the temperature was excluded. This demonstrated that it was possible to cultivate Scenedesmus sp within the temperature range established due to its low significance. Only an increase in vinasse could have a negative impact on the growth. Nonetheless, if increasing concentrations of the effluent were desired, the light intensity should be proportionately higher in order to maintain the same biomass production. The $\mathrm{pH}$ in all the photobioreactors increased to about 7.0-8.0, which was a positive factor considering that vinasse $\mathrm{pH}$ was 4.0. Doria et al.
(2012) and Oliveira (2013) demonstrated the growth of microalgae using wastewater. The results of Oliveira (2013) were similar to those obtained in this study, which obtained a production of $0.48 \mathrm{~g} / \mathrm{L}$ in cultures with $28 \%$ of vinasse. Barrocal et al. (2010) showed that, in batch culture, Spirulina maxima was able to grow on Schlösser medium containing up to $5.0 \mathrm{~g} / \mathrm{L}$ of diluted beet vinasse, reaching biomass concentrations between 3.5 to $4.8 \mathrm{~g} / \mathrm{L}$. The vinasse concentration applied in this study was similar to that used in Marques's (2013), where vinasse concentration was $2.0 \mathrm{~g} / \mathrm{L}$ and biomass concentration was $0.7 \mathrm{~g} / \mathrm{L}$ in a 10 days batch. In this study, the biomass concentration was 
equivalent when the equivalent percentage of vinasse was used. However, vinasse concentration was higher than others available in the literature. Moreover, there was no pre-treatment of the vinasse, as proposed in the literature.

\section{CONCLUSIONS}

This study showed that it was possible to grow Scenedesmus sp. in vinasse, with percentages up to $40 \%$. The maximum point of the exponential phase was achieved between the $6^{\text {th }}$ and $10^{\text {th }}$ day. The factorial design study showed that the use of $50 \%$ vinasse in the culture medium resulted in a smaller amount of microalgae biomass; the Central Composite Design demonstrated that it was possible to cultivate microalgae at concentrations up to $40 \%$ vinasse in the culture medium. This design showed that light intensity and percentage of vinasse influenced the amount of biomass to be produced. Additionally, temperatures between 20 and $35^{\circ} \mathrm{C}$ had no significant effect when working with percentages smaller than $40 \%$ vinasse. Thus, the study demonstrated that vinasse could be used as a nutrient source for microalgae production.

\section{ACKNOWLEDGEMENTS}

The authors would like to thank CAPES (Coordenação de Aperfeiçoamento de Pessoal de Nível Superior - Coordination for the Improvement of Higher Education Personnel) for the study grant; COOPERCANA (Cooperativa dos Produtores de Cana Porto Xavier Ltda - Cane Producer Coop of Porto Xavier LLC) for providing the vinasse.

\section{REFERENCES}

Barrocal VM, García-Cubero MT, González-Benito G, Coca M. Production of biomass by Spirulina maxima using sugar beet vinasse in growth media. $N$ Biotechnol. 2010; 27(6):851-856.

Brennan L, Owende P. Biofuels from microalgae-A review of technologies for production, processing, and extractions of biofuels and co-products. Renew Sus Ener Rev. 2010; 14(2): 557-557.

Buchler PM. The attenuation of underground water contamination in a vinasse clay-lined pond. Water Sci Technol. 1987; 19(12): 183-185.
CETESB. Vinhaça - Critérios e procedimentos para aplicação no solo agrícola 2006. Available from: http://www.cetesb.sp.gov.br/servicos/normas--cetesb/43-normas-tecnicas---cetesb

Chaichalerm S, Pokethitiyook P, Yuan W, Meetam M, Sritong K, Pugkaew W, et al. Culture of microalgal strains isolated from natural habitats in Thailand in various enriched media. Appl Energy. 2012; 89(1):296-302.

Christofoletti CA, Escher JP, Correia JE, Marinho JFU, Fontanetti CS. Sugarcane vinasse: Environmental implications of its use. Waste Manage. 2013; 33(12):2752-2761.

Doria E, Longoni P, Scibilia L, Iazzi N, Cella R, Nielsen E. Isolation and characterization of a Scenedesmus acutus strain to be used for bioremediation of urban wastewater. J Appl Phycol. 2012; 24(3): 375-383.

dos Santos JD, Lopes da Silva AL, da Luz-Costa J, Scheidt GN, Novak AC, Sydney EB, et al. Development of a vinasse nutritive solution for hydroponics. J Environ Manage. 2013; 114(0): 8-12.

España-Gamboa E, Mijangos-Cortes J, Barahona-Perez L, Dominguez-Maldonado J, Hernández-Zarate G, Alzate-Gaviria L. Vinasses: Characterization and treatments. Waste Manage Res. 2011; 29(12):12351250.

Gris LRS, Paim AC, Farenzena M, Trierweiler JO. Laboratory apparatus to evaluate microalgae production. Braz J Chem Eng. 2013;30:487-497.

Marques SSI, Nascimento IA, De Almeida PF, Chinalia FA. Growth of Chlorella vulgaris on sugarcane vinasse: The effect of anaerobic digestion pretreatment. Appl Biochem Biotech. 2013; 171(8):1933-1943.

Navarro AR, del C. Sepúlveda M, Rubio MC. Bioconcentration of vinasse from the alcoholic fermentation of sugar cane molasses. Waste Manage. 2000; 20(7): 581-585.

Oliveira ACd. Produção de biomassa de microalgas Scenedesmus sp. em efluente de bovinocultura biodigerido. Paraná, Brazil: UFPR; 2013. Portuguese.

Stein JR. Handbook of Phycological Methods: Culture Methods and Growth Measurements. 1 ed. Cambridge: Cambridge University Press, 1979.

UNICA. Moagem de cana de açúcar e produção de açúcar e etanol - safra 2011/2012 2012. Available from: http://www.unicadata.com.br/.

Walter A. Bio-Ethanol Development(s) in Brazil. In: Soetaert W, Vandamme EJ, editors. Biofuels. Bélgica: Ghen University, 2009

Zhao G, Chen X, Wang L, Zhou S, Feng H, Chen WN, et al. Ultrasound assisted extraction of carbohydrates from microalgae as feedstock for yeast fermentation. Bioresource Technol. 2013; 128(0):337-344.

Received: November 04, 2013; Accepted: March 11, 2014 